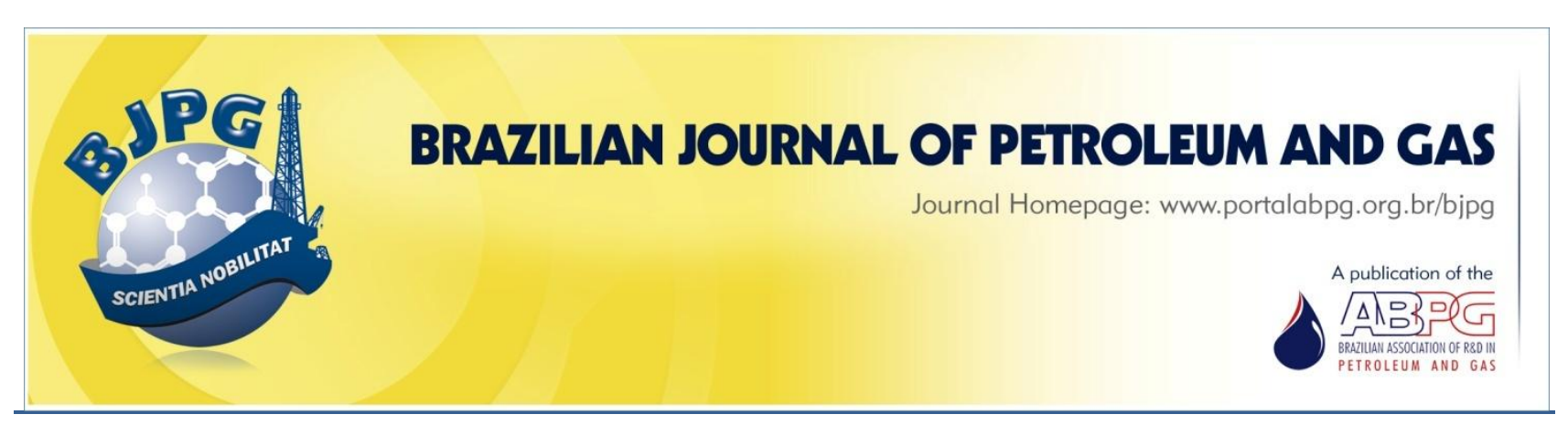

\title{
PETROLEUM EXPORTATION THROUGH PIPELINES: IMPORTANT CONSIDERATIONS
}

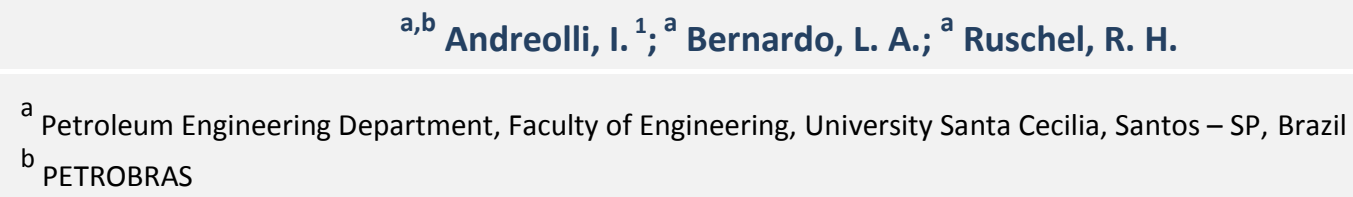

\section{ABSTRACT}

The flow of petroleum through pipelines in deep waters is an alternative that has been adopted in several development projects at the production stage. Some aspects should be considered during the design phase of an exportation system, including the type of oil involved and its characteristics. Very viscous oils predominantly flow in laminar regime and heat transfers cause thermal-hydraulic phenomena responsible for problems, especially during the restart pumping stage. Less viscous oils may also provide flow assurance problems mainly related to gelation due to wax precipitation. This work presents the aspects that should be taken into consideration in the design and installation of an offshore pipeline system, considering the main characteristics of the oil to be exported. Therefore, it identifies alternative forms of flow mitigation able to reduce operational risks, presenting examples of real systems.

\section{KEYWORDS}

exportation oil; pipeline; high viscosity; pressure drop; yield stress

\footnotetext{
${ }^{1}$ To whom all correspondence should be addressed.

Address: University of Santa Cecilia (UNISANTA), Faculty of Engineering, Petroleum Engineering Department, Santos - SP, Brazil. Telephone: +55(13)98831-4526 | e-mail: ivandreolli@gmail.com ; andreolli@petrobras.com.br doi:10.5419/bjpg2015-0007
} 


\section{INTRODUCTION}

Most of the hydrocarbon production in Brazil is concentrated in offshore areas where extensive pipeline sections are installed on the seabed to transport the petroleum. These extensive pipeline sections are submitted to temperatures that could reach $4^{\circ} \mathrm{C}$. However, the oil that flows through pipelines requires specific considerations related to: viscosity, paraffin (wax) deposition, distance between targets, transportation temperature, thermal insulation requirements, subsea heat systems, restart systems, subsea pipeline design, drag reducer applications, and others strategies applied to optimization of oil production, considering oil type (Palou et al., 2011; Bannwart, 2001).

In the case of oil with high viscosity, even considering high volumetric flow rate, the pressure drop has a higher viscosity dependency than that of the oil with low viscosity (Andreolli et al., 2008). If viscosity is extremely high, pressure drop dependency could be directly proportional to viscosity, as observed in the Moody diagram (Moody, 1944) and showed by Bobok et al. (1996) and Farshad et al. (2001). The petroleum viscosity has an exponential dependency on temperature; in other words, thermal considerations are crucial for viscous oil transportation. Therefore, systems that are designed to transport oils in elevated temperatures may provide a better reduction in pressure drop benefiting transient restarts (Andreolli et al., 2008; Andreolli, 2015; Bessa, 2013). Heavy oils are oils that have density corresponding to an $\mathrm{API}^{\circ}$ between 10 and 20 . Extra-heavy oils have densities lower than $10^{\circ}$ API (Palou et al., 2011). According to the International Energy Agency (IEA, 2014), heavy and extra-heavy oil reserves may express a meaningful quantity of recoverable oil resources and technologies have been developed in order to deal with these huge unconventional reserves (Palou et al., 2011; Ghannam et al., 2012). In Brazil, these oil volumes are considered significant volumes and many offshore fields, such as the Papa-Terra, Siri, and Marlin Sul, have been developed and are currently in a production stage, producing oils with densities of up to $13^{\circ} \mathrm{API}$ (Andreolli et al., 2008; Junior et al., 2009).

In the case of low viscosity oils, the flow occurs generally in turbulent regime and thermal aspects are not relevant when related to pressure drop. However, features such as paraffinic content, related to flow assurance aspects, should be considered fundamental, requiring elevated temperatures during oil exportation. Thus, the paraffin in these oils could precipitate, forming deposits on the pipeline wall, increasing pressure drop, during oil transportation, and oil viscosity. In addition, it could cause yield stress during the restart period and also block pipelines (Ajienka \& Ikoku, 1995). Therefore, paraffinic content must be looked at when planning an oil exportation project through pipeline.

Subsea engineering also needs to be acknowledged during project. A project involving the use of wide-diameter pipelines may require special vessels to operate it, potentially increasing the costs, taking into account logistic aspects. Also, this type of operation is often subjected to delays that could increase the costs even more to operators and companies. In addition, the exportation pigging system should be considered, from instrumented pigging to cleaning pigging. Therefore, riser sections (sections that connect platform to seabed) and flowline (sections on the seabed) must be consistent for pigging requiring special care. Flexible risers are implemented frequently, showing diameter limitations when submitted to deep-water sections, considering qualified lines. The installation of parallel pipelines with smaller diameters could be an alternative, simplifying installation and pigging processes. Advantages for the transportation of viscous oils are also recognized once smaller diameters are used. In this case, the system is more robust for restart operation and for low volumetric flow rates, where thermal exchange is lower due a reduction in the area that is in contact with seawater. (Bessa, 2013; Andreolli, 2009).

Application of drag reducers could also be relevant during production peak. They act to mitigate the increase of turbulent eddies by absorbing the released energy by the breakdown of the lamellar layers (Palou et al., 2011). Depending on the turbulence of the flow, drag reducers could improve transportation system capacity, allowing the implementation of smaller diameter pipelines. During the first years production peaks occur at high volumetric flow rates. Therefore, the usage of drag reducers in small diameter pipelines could present technical and economical advantages if 
compared to large diameter pipelines used in the first few years of production peak. Although drag reducers have good performance when applied to turbulent transportation, they no longer can be well applied to high viscous oil (Wahaibi et al., 2007; Graham, 2004; Toonder, 1997). Drag reducers have been used in the Brazilian scenario showing effective results (Bernardo \& Andreolli, 2014).

The type of the oil to be transported is also fundamental for designing and planning the exportation project. In addition, permanent and transient flow analyses are also crucial for project development. However, in the simulation of an oil exportation scenario, computer tools are required order to evaluate the system. For example, the increase of temperature might show relevant aspects in terms of oil flow capability when this oil is considered viscous, what might influence the strategies to be adopted in the project.

Thermal insulation could bring benefits to both types of petroleum, more viscous and less viscous ones. But, for the less viscous oil type, thermal insulation could also help to reduce problems related to paraffin content, avoiding high pressure drop and improving performance during the restart production period. In the case of extensive pipelines, thermal insulation by itself was not enough to mitigate paraffin problems, so other strategies must be adopted, such as the use pigging to remove paraffin deposits (Junior et al., 2009; Bessa, 2013; Andreolli, 2009).

Application of computer tools is important to properly define the petroleum exportation system through pipelines, including the transient analysis, which is essential when dealing with oils containing high viscosity (Barnes, 1979; Andreolli et al., 2008). With the improvements in technologies, computer software can create accurate models to obtain high accuracy on modeling fluid phase. Viscous oils exportation requires high performance on the development of thermal exchange model because of strong relation between pressure drop and thermal profile. Moreover, considerations on one-dimensional model where an average temperature is adopted in each exportation section were no longer adequate. It could be explained by a radial temperature gradient and a variation on the exportation velocity profile due to this radial gradient. In addition, this variation might modify the thermal exchanges as well as pressure drop. In this case, a Computational Fluid Dynamic (CFD) could be required (Andreolli et al., 2008; Farshad et al., 2001).

Special cares are necessary in case of nonNewtonian fluids. If the petroleum has yield stress at low temperatures, risks could appear during exportation restart after a long non-production period. The modeling phase of these systems is complex and accurate analytical models are under development. In this scenario an auxiliary cleaning oil system could be implemented during the long non-production period. In addition, electric heating, or pipe-in-pipe system containing heat fluid, could also be in place. In this case, exportation complexity is acknowledged, and it might be an alternative to use vessels to export the oil, instead of using pipelines (Junior et al., 2009; Palou et al., 2011; Ghannam et al., 2012; Barnes, 1979).

The oil transportation through pipelines still is the most conventional and economical technique (Ghannam et al., 2012). A wide variety of other techniques have been developed and applied successfully in order to prove technical and economical viability of oil transportation through pipelines. For example, according to Ghannam et al. (2012) and Degiorgis et al. (2001) dilution of light oils into heavy oils has been applied to improve fluid flow.

This article reveals relevant aspects that should be taken into considerations to develop and implement an offshore pipeline system, considering the main characteristics of the oil to be exported. Thus, a detailed study was developed in order to provide a permanent and transient approach during exportation process, comparing two different types of oils, the first, a high viscosity one and the second, a less viscous one. Important aspects to be considered in a project will be shown through different exportation system scenarios.

\section{METHODS}

This work aims to show important aspects to be considered for oil exportation projects through pipeline. Oil exportation scenarios will demonstrate the approach of each important aspect. In addition, computational tools will be also 


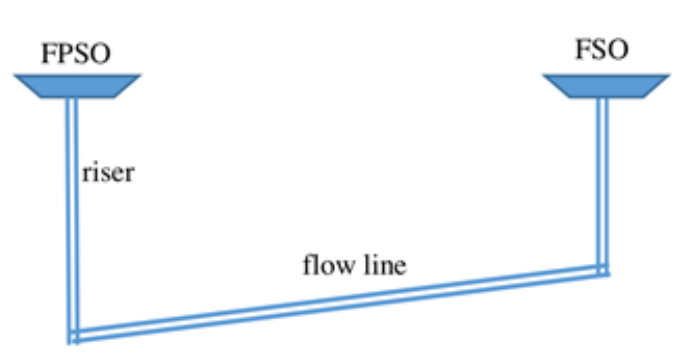

Figure 1. Approached System.

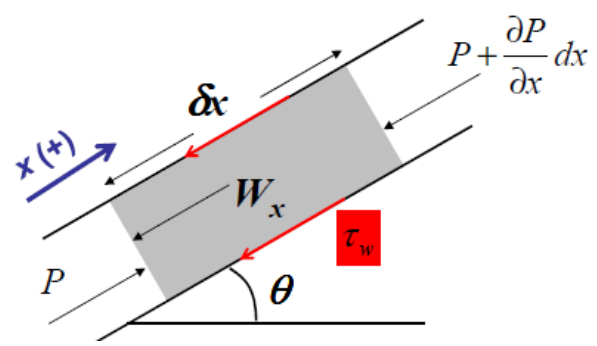

Figure 2. Force decomposition.

implemented to simulate and analyze these scenarios. The aspects that will be presented are: (i) very viscous oil flow against less viscous oil flow, (ii) drag reducers application, (iii) oil-flow modeling, (iv) subsea engineering considerations, and (v) nonNewtonian oil flow. Figure 1 illustrates a pipeline connection between a FPSO and a FSO, presenting a general approach of this work. This system consists in two risers and one flowline section, both with the same diameter. For this system, one will consider continuity balance and one-dimensional motion. Momentum balance determination is shown in Figure 2.

The continuity balance equation is given by Eq. 1. The first term computes the mass variation with time in the control volume and the second term represents the mass flux in the boundaries of the control volume, which sum should be zero.

$$
\frac{\partial \rho}{\partial t}+\frac{\partial(\rho V)}{\partial x}=0
$$

The momentum balance equation in a conservative mode could be obtained through a differential process applied to force balance in Figure 2, resulting in Eq. 2.

$$
\frac{\partial(\rho V)}{\partial t}+\frac{\partial\left(\rho V^{2}\right)}{\partial x}+\frac{\partial P}{\partial x}=-\rho g \operatorname{sen}(\theta)-\tau_{w} \pi \frac{D}{A}
$$

The last term of Eq. 2 is related to pressure drop by friction force. However, applying dimensional analysis, shear strain $\left(\tau_{w}\right)$ could be eliminated by adding a friction factor (f), which is a function of Reynolds number and relative roughness, as shown in Eq. 3. Friction factor is determined through Moody diagram. Experimental studies developed by Moody in 1944 allowed improvements in the hydraulic field, specifically for turbulent transport where there is no until exact equation to estimate pressure drop (Pope, 2000). Turbulent scale theory, as presented by Kolmogorov (1941), and the dynamic systems also brought improvements in the area, but such improvements could no longer be equated in analytical form (Pope, 2000; Tennekes \& Lumley, 1972; Jiménez, 1991; Jiménez, 2004).

$$
\left\{\begin{array}{l}
\tau_{w} \pi \frac{D}{A}=\frac{1}{2} \rho f \frac{|V| V}{D} \\
f=F\left(\operatorname{Re}, \frac{\varepsilon}{D}\right) \rightarrow \text { Moody }
\end{array}\right.
$$

Considering Eq. 3 for friction and substituting on Eq. 2, results in Eq. 4, which is one-dimension transient motion equation for single-phase flow in pipelines.

$$
\frac{\partial(\rho V)}{\partial t}+\frac{\partial\left(\rho V^{2}\right)}{\partial x}+\frac{\partial P}{\partial x}=-\rho g \operatorname{sen}(\theta)-\frac{1}{2} \rho f \frac{|V| V}{D}
$$

However, considering that oil flow can be classified as an incompressible flow and also that the pipeline diameter will not vary significantly, the acceleration term can be neglected. In addition, as this oil flow is between two platforms, gravitational term can also be ignored. Finally, considering permanent analysis, the time-related term is also neglected, consequently, generating Eq. 5 .

$$
\frac{\partial P}{\partial x}=-\frac{1}{2} \rho f \frac{|V| V}{D}
$$

As pressure gradient is constant and considering isothermal flow, analytical integration of Eq. 5 results in Eq. 6, where pressure drop (HP) gives fluid column height in meters. It is notorious that pressure drop depends on pipeline geometric factor, volumetric flow rate (velocity) and friction factor. 


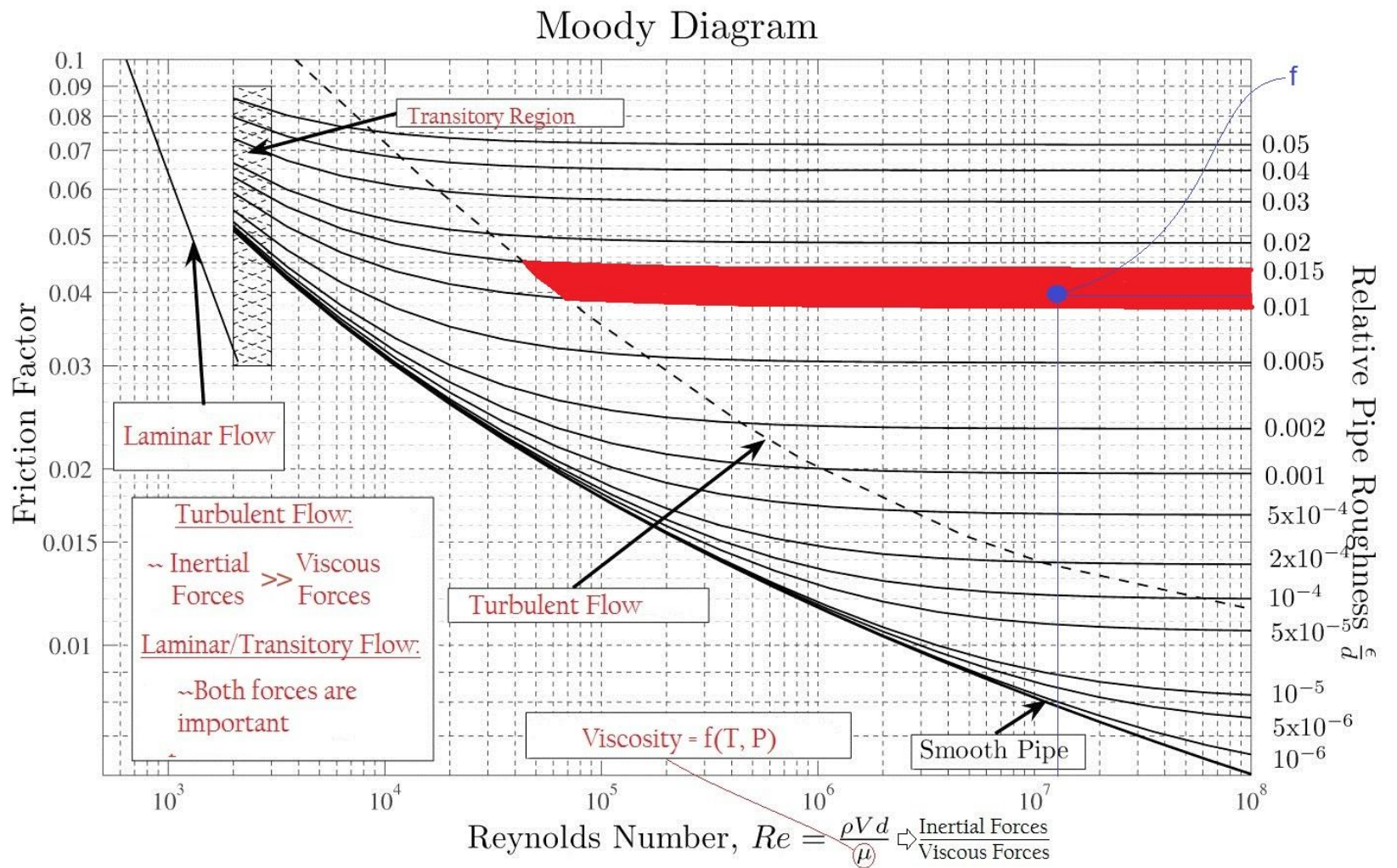

Figure 3. Moody Chart.

$$
H P=\frac{f L V^{2}}{2 g D}
$$

\subsection{Viscous oil flow and less viscous oil flow - the mechanics}

Flow modeling phase is fundamental in the design of an oil exportation system in an offshore environment. However, is indispensable to understand petroleum rheology. Less viscous oils flow have a turbulent behavior. This scenario reveals that pressure drop has no significant dependency on oil viscosity. On the other hand, viscous oil flow, even when submitted to great flux velocity, tends to be laminar or less turbulent (Andreolli et al., 2008; Palou et al., 2011; Junior et al., 2009). In this case, pressure drop has a strong dependency on viscosity. Figure 3 shows the flowchart of the mechanics of a viscous oil flow. The highlighted region in red color reveals the behavior of a less viscous oil flow, which is a considered predominantly turbulent flow due to inertial forces presented.
The main difference between viscous and less viscous oil flow is the flow regime. Due to high turbulence in less viscous oil flow, inertial forces are predominant and friction factor does not depend on Reynolds number, as observed in the highlighted area of Figure 3. Therefore, pressure drop is no longer influenced by thermal variation of oil flow that modifies average viscosity. In this case, pressure drop might be approximated by a constant, which includes friction factor multiplied by square volumetric flow rate. However, for viscous oil flow, the viscous forces are relevant and viscosity dependence is directly proportional to pressure drop. This scenario reveals that pressure drop is influenced strongly by oil viscosity and thermal phenomena are important, especially as one can verify the exponential dependency of viscosity on temperature.

The direct pressure drop dependency on viscosity for very viscous oil flow is summarized on Eq. 7, where friction factor of laminar regime is substituted on Eq. 6, and it reveals that pressure drop depends on volume and viscosity. 


$$
\left\{\begin{array}{l}
\overbrace{\begin{array}{l}
H P=\frac{f L V^{2}}{2 g D} \\
f=\frac{64}{\mathrm{Re}}
\end{array}}^{\text {LAMINAR FLOW }} \rightarrow \\
\begin{array}{l}
H P=\frac{32 V \mu L}{D^{2}}=C 2 \cdot Q \cdot \mu \\
\mu \propto \exp (T) \rightarrow H P \propto Q \cdot \exp (T)
\end{array}
\end{array}\right.
$$

Analogously, for fully turbulent flow, one can observe, through the Moody diagram, that friction factor ( $f$ ) does not change significantly. Thus, this parameter can be assumed constant. Then, considering that and substituting it on Eq. 6, generates Eq. 8. Equation 8 shows that pressure drop, in an approximate approach, does not depend on viscosity, it depends exclusively on square volumetric flow rate.

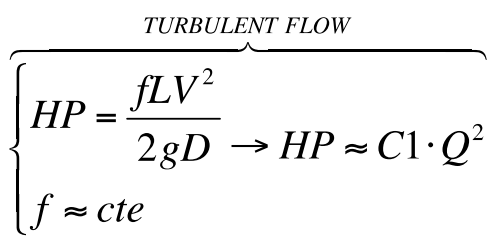

These mechanical behavior differences between very viscous oil flow and less viscous oil flow will be shown in a case study of thermal exchanges later in this work. These differences lead to an uncommon behavior of pressure curves that are required to pump very viscous oils with thermal exchange and also implies the necessity of mitigation strategies for flow assurance, mainly in restart flow periods. Flow modeling becomes fundamental in order to evaluate the entire flow system of a project. The flow modeling is important to estimate exportation capacity, determine thermo-hydraulic profiles for pipeline structural design, evaluate the restart of the pumping phase, and respond operational questions during transient flow (Peysson et al., 2005).

In the results and discussion section, the importance of accurate thermal modeling for high viscous oils will be evaluated. The flow regime is considered predominately laminar. The impact of imprecise thermal modeling design in pressure drop, considering high viscous oils and conventional oils, will be examined in the case study. Due to very viscous oils having a laminar flow regime, one-dimensional modeling is not appropriate. In this case, Poiseuille profile is generated from the one-dimensional analysis considering an average temperature. In real scenarios, viscosity variation occurs radially and longitudinally in each point of flow section, modifying the velocity profile. Three-dimensional analysis would be more accurate to evaluate permanent and transient hydraulic profile. This work required applications of two different simulators: Olga ${ }^{\circledR}$, which is a one-dimensional simulator implemented to permanent and transient analysis, and PVTsim $^{\circledR}$, which is a thermodynamic simulator that provides fluid characterization facilities.

\subsection{Pipeline projects: general considerations}

For oil flow systems in offshore environments, there is always a concern about using large diameter pipelines. However, large diameter pipelines are heavier and more difficult to install and operate. Robust offshore equipment installation, including large diameter pipelines, is considered a complex task that requires special vessels and conditions. In addition to that, financial assessment estimates the operation costs considering that these operations generally are expensive and could be delayed due to many factors.

Small diameter pipelines could be an alternative to flow assurance. Thus, it might be interesting to design oil exportation systems containing small diameter pipelines able to guarantee total oil production exportation.

An alternative to reduce the pipeline diameter is the application of drag reducers. Drag reducers are implemented in order to reduce mechanic losses by friction during oil flow. They work reorganizing long chain linear molecules that are submitted to turbulent regime, reducing the energy released. Therefore, this reduction leads to less turbulence during fluid flow, decreasing losses by friction (Wahaibi et al., 2007; Graham, 2004; Toonder, 1997). These products are generally long chain polymers, containing high viscosity. When added few dozens of ppm (part per million) to fluid flow fraction, they promote a fluid flow rearrangement, reducing turbulent motion and consequently, reducing pressure drop. However, 
polymeric chain should be preserved when submitted to drag reducer addition. These drag reducers should be added downstream of the centrifugal pump where there is no rupture of polymer chains. Generally, 20 to $70 \mathrm{ppm}$ are injected using pneumatic pumps. These products have been used in several cases of oil flow, as reported by Bernardo and Andreolli (2014). Nevertheless, these products are expensive and should be avoided as much as possible. Although, depending on scenario, it might be interesting to use chemical products during initial phase of the exportation oil project, as one may see in the results and discussion section of this work.

Another relevant aspect related to the oil exportation project is the study of petroleum rheology. Different oil types present substantial deviation related to Newton viscosity law and might be recognized as non-Newtonian fluids. In the oil and gas industry, non-Newtonian fluids have a wide range of applications, from the oil produced (paraffinic oils) to fluids used for drilling and completion operations, such as, cements and drilling fluids (Bourgoyne et al., 1991; Junior et al., 2009; Bessa, 2013; Andreolli, 2009).

Two different aspects characterize Newtonian deviation: yield stress during oil flow and viscosity variation, measured with shear strain variation (dV/dr) (Desouky, 1991). However, in pipelines, non-Newtonian behavior is related mainly to very viscous oils and to less viscous oils due to paraffin precipitation (Cardoso et al., 2003). The modeling of this type of system is deemed complex as one can find in current studies in this area presented by Mendes et al. (2012).

A general equation for non-Newtonian fluids is presented in Eq. 9. Comparison to Newtonian fluid reveals that the difference is related to power factor $n$ and yield stress. This model shows that viscosity is influenced by shear rate. Besides, there is a yield stress $\left(\tau_{\text {lim }}\right)$ to be overpassed in order to begin oil flow due to oil gelling (paraffinic oil feature), but it is not limited to this oil type (Machado, 2002; Dodge \& Metzner, 1959).

$$
\tau=\tau_{\lim }+K\left(\frac{d V}{d r}\right)^{n}
$$

The shear rate dependency becomes a oil flow modeling complex due to a wide database from laboratory to be considered. The viscosity was measured for each combination of shear rate and temperature. Further on this study, a simple form of pressure estimation that is required for pump will be presented, overpassing static friction force. In addition, alternatives to reduce the risk of pipeline blockage will be revealed. Moreover, strategies to make these pipelines into feasible subsea systems will be presented, as well as their advantages from the beginning to the end of oil exportation operation. Thermal modeling aspects will be also shown.

\section{RESULTS AND DISCUSSION}

This section will present an analysis for each item approached during previous sections. It will also show important aspects of projects for oil flow through pipeline. Transient simulator, Olga ${ }^{\circledR}$, and thermodynamic PVTsim ${ }^{\circledR}$ were applied.

\subsection{Viscous oils against less viscous oils}

In this case, the system under analysis (Figure 1) consists of a pipeline system of $20 \mathrm{~km}$ long, 12 inches intern diameter, and about 3.5W/(m.K) TEC (Thermal Exchange Coefficient), connecting two deep water platforms located in Southeast region of Brazil, with bottom temperature ranging around $4^{\circ} \mathrm{C}$. Table 1 presents a few measured viscosities for two oil types (very viscous and less viscous).

Analyzing the pressure curves required to pump the oil from FPSO, and considering single-phase viscous oil in permanent regime, one could observe that required pressure peak occurs during low volumetric flow rates. Figure 4 presents a typical viscous oil curve from a hypothetic oil pipeline located offshore. Figure 4 also illustrates less viscous oil curve in orange color.

Table 1. Measured viscosity from the two studied oils.

\begin{tabular}{ccc}
\hline $\begin{array}{c}\text { Temp } \\
\left({ }^{\circ} \mathrm{C}\right)\end{array}$ & $\begin{array}{c}\text { Viscosities } \\
\text { (cP) }\end{array}$ & $\begin{array}{c}\text { Viscosities } \\
\text { (cP) }\end{array}$ \\
\hline & ${ }^{\circ} \mathrm{API} 15.6$ & ${ }^{\circ} \mathrm{API} 24.6$ \\
4 & 40000 & 200 \\
40 & 1000 & 30 \\
60 & 250 & 15 \\
& &
\end{tabular}




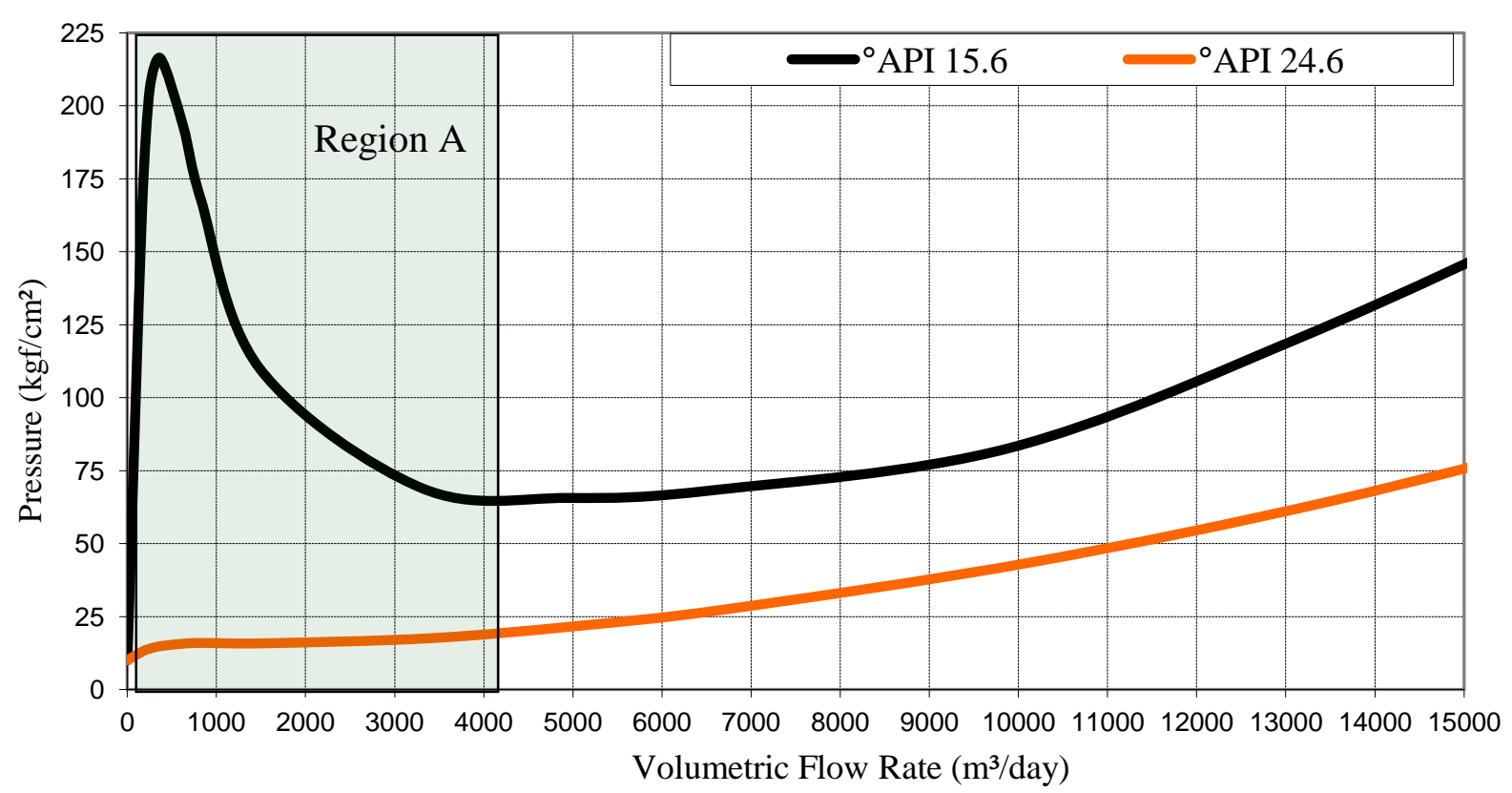

Figure 4. Required pressure in function of volumetric flow rate (steady state).

The first extreme point (region A) observed during very viscous oil flow (black curve) indicates that, for permanent regime, pumping pressure is higher during low volumetric flow rates than high volumetric flow rates. For example, pumping $1000 \mathrm{~m}^{3} /$ day requires a higher pressure than pumping $6000 \mathrm{~m}^{3} /$ day. This is a phenomenon that is characteristic of viscous oils, justifying long restart periods in this system. In addition, the hump observed on the viscous oil curve might be explained by Moody diagram (Figure 3). When the volumetric flow rate increases in a pipeline, temperature also increases after reaching permanent flow. Consequently, exponential viscosity reduction happens. Analyzing pressure drop equation (Eq. 7) one can notice that pressure drop rises linearly with volume, but decreases exponentially with temperature in terms of viscosity. Therefore, the extreme point is explained by the fluid behavior described above and observed in the highlighted region A of Figure 4. During the first graph section, when volumetric flow rate has lower values, the required pressure increases with volumetric flow rate. In most of cases, the fluid has low temperature and the thermal effects are not enough to affect viscosity during oil flow and, consequently, to produce pressure drops.
However, at high volumetric flow rates, pipeline temperature increases, leading to an exponential reduction of viscosity. Furthermore, viscosity reduction implies on pressure drop reduction, even when flow velocity increases. But, since the temperature is already high, viscosity will not change with higher volumetric flow rates, which is justified by the minor thermal exchange with seawater. In addition, inertial forces are predominant as velocity is already high, leading to a turbulent regime.

The hump phenomenon, that could be explained by fluid mechanics, happens also due a to thermal phenomenon that has exponential relation with viscosity. Moreover, this is a characteristic of viscous oils related to flowing type. However, it is acknowledged that this hump brings consequences related to oil flow after a long non-production period. In addition, during viscous oil flow, a critical aspect is related to restart periods (Andreolli, 2009). Furthermore, due to high viscosity rates during low temperatures, restart pumping might be extremely slow, making pumping relatively unfeasible since centrifugal pumps operate in a determined flow rate range. Even though it is a Newtonian fluid, initial restart flow rates are extremely low for viscous oils. 


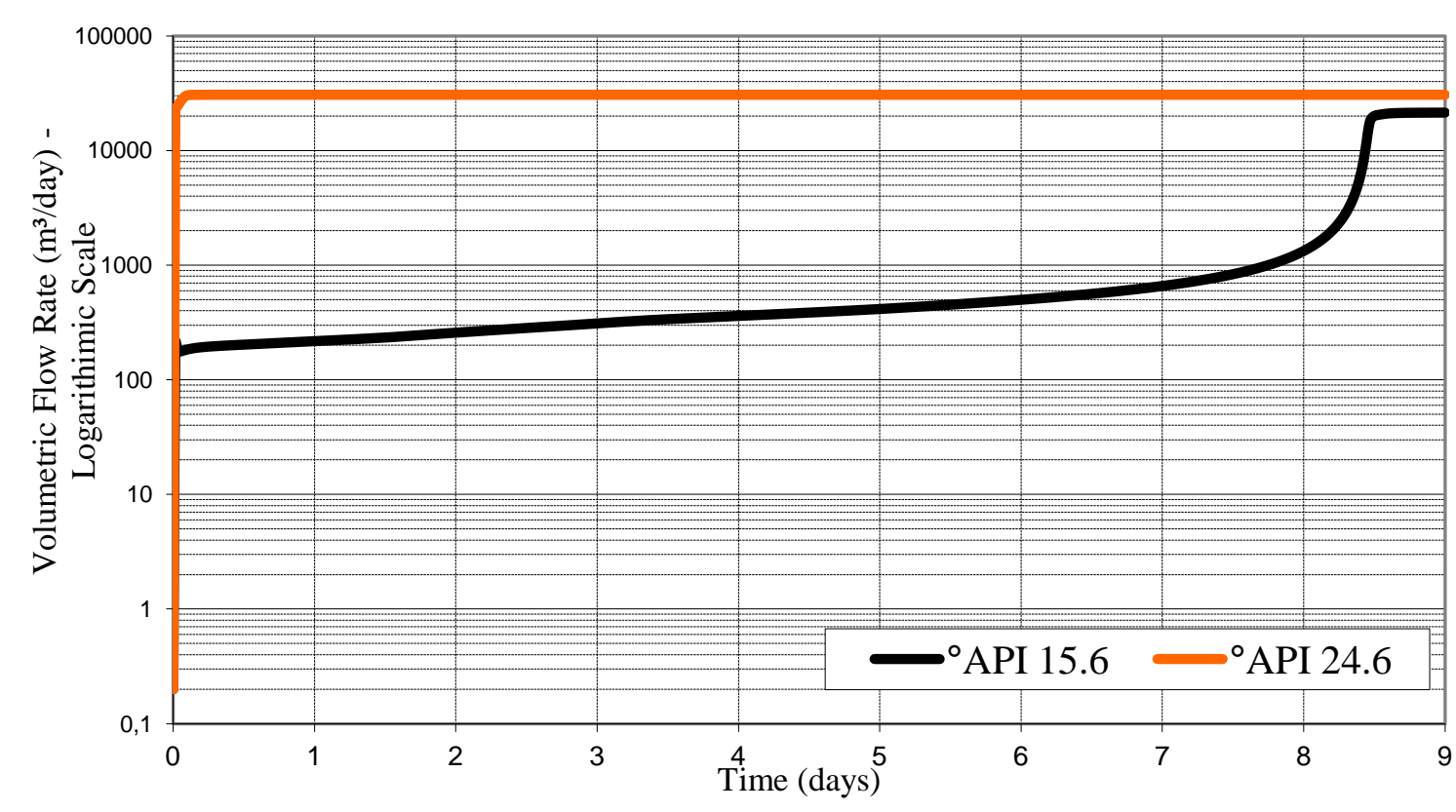

Figure 5. Transient restart oil pipeline curves.

Moreover, in case of very viscous oils it is interesting to avoid restart risks, seeking mitigation strategies. Figure 5 presents in logarithmic scale the restart flow of an oil pipeline thermally isolated and $20 \mathrm{~km}$ long for both types of petroleum.

This analysis was obtained through transient simulation at the $\operatorname{Olga}^{\circledR}$ simulator. It is notorious that constant flow rate for less viscous oil is reached rapidly while for more viscous oil it takes more than a week to reach it.

In Figure 4, if the hump presents a sharp curve, it might indicate that it could not be feasible to deal with restart operations. In addition, permanent flow rates may be lower than peak flow rates (sharp curve). This could happen when the pressure of the pump system has a lower capacity than the peak flow rate pressure, decreasing flow rate after a sharp curve. Moreover, if the fluid is non-Newtonian and has yield stress, there is a risk of static friction force being higher than the pump system capacity. Therefore, it is extremely important to provide a well-designed and developed oil exportation project in order to avoid operational risks, and also supply solutions that could mitigate problems. These mitigating systems are: (i) heat systems such as, electric heating or pipe-in-pipe systems, which use a hot water circulation system (Dixon, 2013; McDermott \& Sathananthan 2014; Junior et al., 2009); (ii) cleaning pipeline systems (Andreolli, 2009); (iii) blend between light and heavy oils in order to reduce viscosity (Palou et al., 2011; Degiorgis et al., 2001); and (iv) shared exportation, mixing oils from different fields (Palou et al., 2011; Andreolli et al., 2008). Restart operations become easier when submitted to heat systems.

Critical temperature could be identified through transient simulations. In terms of flow restart, it might be possible to design a heat system to raise temperature from $4^{\circ} \mathrm{C}$ to a critical temperature that was previously identified (McDermott \& Sathananthan, 2014). However, the heating system would be utilized until average flow rate is reached at critical temperature, being turned off afterwards. In addition, one must acknowledge that these complex heating systems require different equipment that demand space and energy on the platform.

A common cleaning system that is implemented in offshore environments is the diesel oil pump system. This system operates at high performance, pumping diesel to pipelines. It is also applied in emergency situations, such as shutdown events. Before system implementation, a cause-effect risk assessment should be done to evaluate the entire diesel pump system, analyzing relevant aspects such as critical temperature and oil-cooling time during the cleaning event. 
An oil blend might also be an alternative. It consists of a blend of different oil types, such as light and heavy oils, in order to reduce viscosity. For example, during the restart period less viscous oil wells might be opened first in order to mitigate flow problems. After reaching a permanent flow regime, more viscous oil wells could be also opened increasing volumetric flow rate and raising the temperature at the pipeline. When the average flow is reached, the oil blend composition will contain light and heavy oils with reduced viscosity and, consequently, will reduce pressure drop and operational risks, mainly on the next restart time.

Shared exportation helps in terms of viscosity reduction, decreasing operational risks. During a non-production time period, less viscous oil production system may substitute existing more viscous oils in pipeline. Moreover, during advanced production stage, when volumetric flow rates are lower, shared exportation system might maintain average volumetric flow rates with high flow temperatures, ensuring flow assurance aspects.

Many of the strategies mentioned above were implemented on Papa-Terra production field, located at Campos Basin, Brazil (Junior et al., 2009). The oil produced in that location has ${ }^{\circ} \mathrm{API} 13$ and is exported from a TLWP (Tension Leg Wellhead Platform) to an FPSO vessel. Another example of flow system that has been implemented at Campos Basin is between FPSO and FSO, which is described by Andreolli et al. (2008).

Table 2. Data obtained in field with friction reducer application from Campos Basin oil pipeline.

\begin{tabular}{ccccccc}
\hline & $\mathrm{C}$ & $\mathrm{Q}$ & $\mathrm{L}$ & $\mathrm{Re}$ & & $\mathrm{PP}$ \\
Pipe & $\begin{array}{c}\mathrm{H} \\
(\mathrm{vppm})\end{array}$ & $\begin{array}{c}\left.\mathrm{m}^{3} / \mathrm{d}\right) \\
(\mathrm{m})\end{array}$ & $\begin{array}{c}{ }^{3} \mathrm{API} \\
\text { (bar) }\end{array}$ & $\begin{array}{c}\text { reduction } \\
\left(\% 0^{3}\right.\end{array}$ & $10^{*}$ \\
\hline
\end{tabular}

$\begin{array}{lccccccc}\text { O1 } & 80 & 10.2 & 7.5 & 37 a 16 & 25 & 65 & 35 \\ \text { O2 } & 85 & 13.0 & 35.0 & 12 \text { e } 9 & 24 & 170 & 28 \\ \text { O3 } & 38 & 10.0 & 18.7 & 33 \text { a } 6 & 23 & 170 & 26 \\ \text { O4 } & 80 & 7.8 & - & 8 & - & - & 41 \\ \text { O5 } & 80 & 7.4 & - & 10 & - & - & 24 \\ \text { O6 } & 80 & - & - & - & - & - & 37 \\ \text { 07 } & 125 & - & - & - & - & - & 42\end{array}$

*Average data acquired taking into considerations system oscillations

\subsection{Drag reducer's implementation}

This alternative has been adopted where exportation systems were overestimated due to lack of accuracy on project design or changes on production system, such as new connections between platforms or extension project application.

During the first few years of production, a feasible application of a drag reducer would consist in the implementation of smaller diameter pipelines, as maximum capacity is only reached during first few years of production. Nevertheless, conducting an economic analysis prior to starting the implementation would be advisable to avoid wasting resources.

Thus, the most common use is related to the improvement of the exportation system capacity. This work will analyze a case study about it. Also, three oil exportation systems $(\mathrm{O} 1, \mathrm{O} 2$, and $\mathrm{O} 3)$ will be discussed. However, these three oil exportation systems were summarized on Table 2 , including other four cases recorded in the application of drag reducer in Brazil $(04,05,06$, and 07). This study was developed at the Campos Basin.

The pipeline length of exportation system $\mathrm{O} 1$ is $35 \mathrm{~km}$. Sections with smaller diameters were installed in order to anticipate oil production. In addition, drag reducers were used to improve production. In terms of pressure drop one could notice a reduction of $35 \%$ with dosage of $80 \mathrm{vppm}$ (volumetric part per million). However, the excellent result was due to the oil's turbulent regime. Exportation system $\mathrm{O} 2$ consisted of two 7 $\mathrm{km}$ parallel oil pipelines with 7 in diameter. The same drag reducer type was applied due to a new riser implementation. As this system is also characterized by turbulent regime and concentration of $70 \mathrm{vppm}$, pressure drop reduction was in $28 \%$. The third system (O3) was given by a system of three pipelines with a delay on connections between pipelines. Initially, just one of three oil pipelines was available for oil flow, with an extension of $19 \mathrm{~km}, 9$ in diameter, and concentration of $40 \mathrm{vppm}$. Drag reducer application improved production and pressure drop reduction was in $26 \%$, as regime was considered turbulent.

Table 2 summarizes the results obtained for those three systems where information is related 


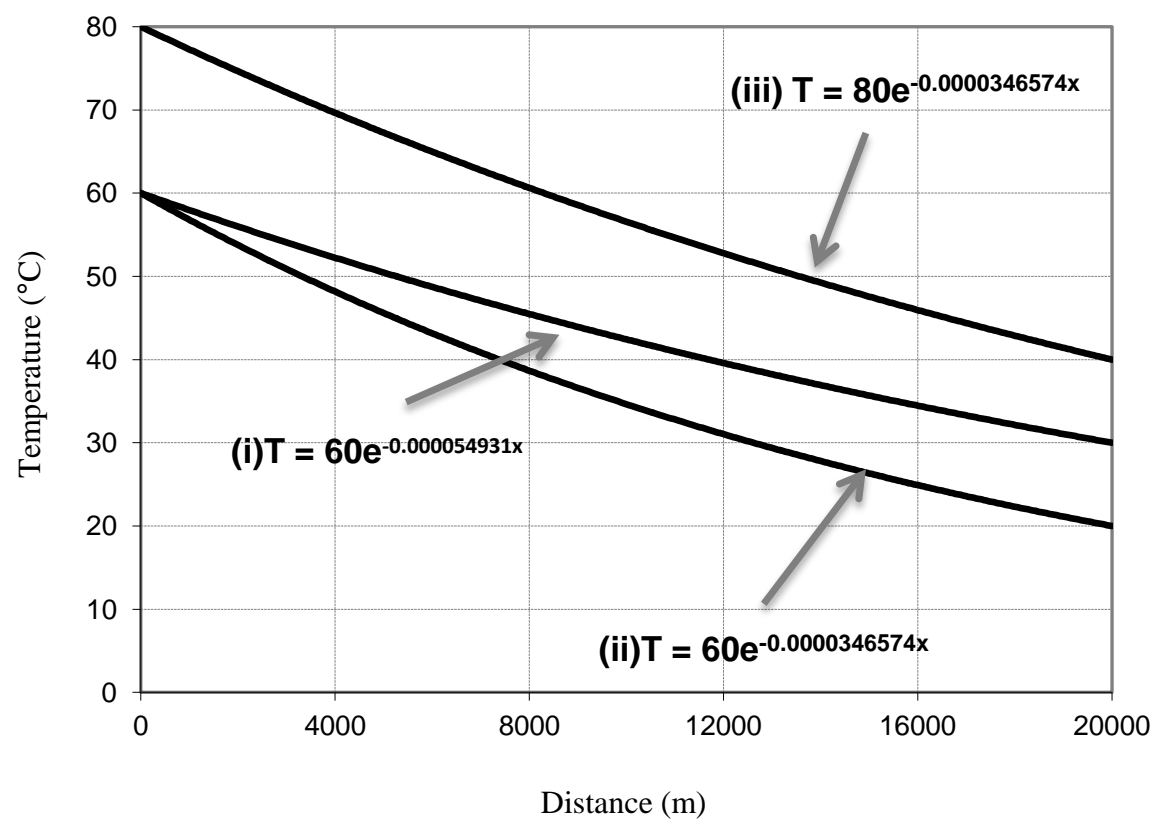

Figure 6. Pipeline thermal profile considering: (i) reaching $30^{\circ} \mathrm{C}$; (ii) uncertainty, reaching $20^{\circ} \mathrm{C}$; and (iii) increasing on exportation temperature to $80^{\circ} \mathrm{C}$.

to: pipeline length, product concentration (C), volumetric flow rate before drag reducing application $(\mathrm{Q})$, total length including riser section (L), Reynolds number (Re), oil ${ }^{\circ} \mathrm{API}$, maximum discharge pressure (PB), and percentage of drag reducer reduction (HP).

The drag reducer scenario is wide, providing diverse products with different performance and costs. Field analysis is extremely important in order to obtain product selection accuracy. Moreover, drag reducers application has demonstrated to be an alternative for reduction of pipeline diameter without causing productivity losses (pressure drop). Based on the information acquired in computational tools, it is possible to predict production during the first few years. In addition, economical and risk analysis must be done in order to well define future strategies related to pipeline installation, equipment utilization, pigging system, special vessels requirement, and volumetric flow rate reduction along the years.

\subsection{Flow modeling}

The flow modeling stage is one of the most important stages in the design of an oil exportation system, ensuring flow assurance during oil production. Also, is important to assure structural point of view as well as select desirable pumps for the oil exportation project. During the oil modeling phase one should consider hypothesis of incompressible fluid flow, but thermal exchanges must be also acknowledged. In order to predict thermal exchanges, simulators should be used. In terms of developing a successful oil exportation project, pressure drop appears to be a critical problem. However, this problem is more likely to happen for laminar regime, in other words, during more viscous oil flow. As mentioned before in this work, for laminar regime cases, pressure drop has a direct dependency on viscosity and viscosity has an exponential dependency on temperature. However, in Moody diagram (Figure 3) one could observe a transition phase, between laminar and turbulent flow. In this case, pressure drop has also a strong dependency on temperature.

In order to show the influence of temperature on pressure drop, a pipeline of $20 \mathrm{~km}$ long and 12 inches diameter was taken into account (Figure 1). In addition, thermal profiles are shown in Figure 6, where such aspects were considered: (i) input temperature of $60^{\circ} \mathrm{C}$ and output temperature of $30^{\circ} \mathrm{C}$ for simulated profile; (ii) non accurate profile 


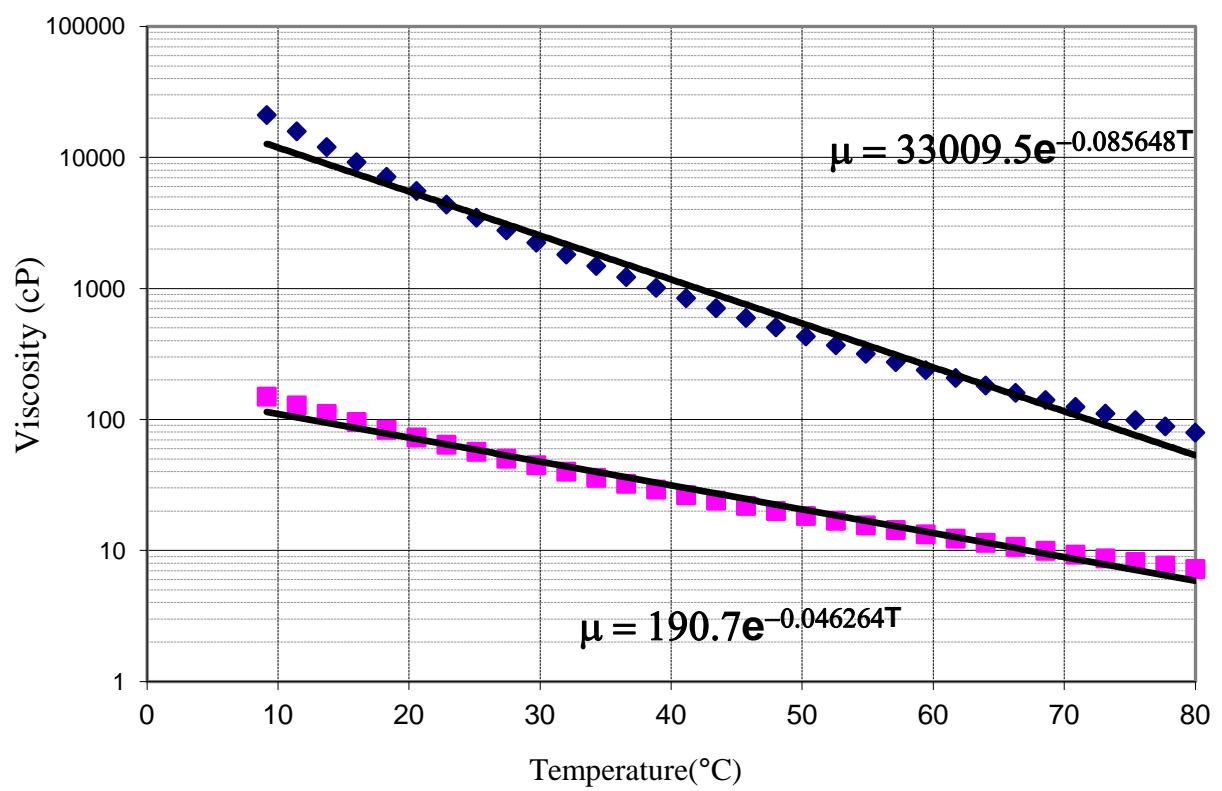

Figure 7. Viscosity curves for both oil types.

with input temperature of $20^{\circ} \mathrm{C}$; (iii) input temperature of $80^{\circ} \mathrm{C}$ instead of $60^{\circ} \mathrm{C}$. Figure 7 reveals viscosities for both types of oils (very viscous and less viscous oils). Moreover, pressure drop for both oils was calculated considering the three thermal profiles of Figure 6. Pressure drop results are shown in Table 3 where friction factor was looked at as (f) a function of Reynolds number or viscosity.

It is observed that there are minimal variations on pressure drop with temperature variation in less viscous oils while for more viscous oils,

Table 3. Comparison between systems submitted to different conditions. HP is the pressure drop given in meters

\begin{tabular}{cccc}
\hline $\begin{array}{c}\text { Oil } \\
{ }^{\circ} \mathrm{API}\end{array}$ & $\begin{array}{c}{ }^{*} \mathrm{HP}, \\
\mathrm{T}=60^{\circ} \mathrm{C} / 30^{\circ} \mathrm{C}\end{array}$ & $\begin{array}{c}{ }^{*} \mathrm{HP}, \\
\mathrm{T}=60^{\circ} \mathrm{C} / 20^{\circ} \mathrm{C}\end{array}$ & $\begin{array}{c}* \mathrm{HP}, \\
\mathrm{T}=80^{\circ} \mathrm{C} / 40^{\circ} \mathrm{C}\end{array}$ \\
\hline 25 & 107.0 & 108.1 & 105.8 \\
16 & 181.4 & 380.2 & 121.7 \\
\hline
\end{tabular}

* For pressure in $\mathrm{kgf} / \mathrm{cm}^{2}$ temperature has a strong impact on pressure drop. In terms of thermal uncertainty, variation of $10^{\circ} \mathrm{C}$ might imply in an exponential increase in pressure drop. To conclude, increment of exportation temperature results in meaningful reductions on pressure drop for more viscous oil flow, but it is almost inexpressible for less viscous oil flow.

There are few alternatives to increase exportation temperature and one of the most used is thermal insulation. However, for less viscous oil flow, this solution does not represent substantial improvement, as it has a turbulent regime. On the other hand, in terms of flow assurance aspects it's important to avoid paraffin precipitation. In case of more viscous oil flow, thermal considerations are fundamental due to laminar flow regime, and a three-dimensional analysis should be done in order to obtain accurate results.

Generally, flow simulators present onedimensional analysis, adopting an average temperature for each flow section that results in Poiseuille velocity profile in case of laminar flow. In addition, viscosity varies radially according to temperature variation, while thermal exchange and velocity profiles are influenced by this variation and should be considered in pressure drop calculation. 


\subsection{Subsea engineering considerations}

Pipelines and reduced size equipment show advantages for installation. Large diameter pipelines, above 12 inches, are generally connected to flexible risers, which have smaller diameters- 9 inches (Cardoso et al., 2003). This diameter variation might provoke pigging problems that include cleaning pigging and instrumented pigging. In this case, installing two smaller parallel diameter pipelines may appear as a great solution. In addition, as parallel pipelines have a smaller diameter, they allow more operational flexibility. For example, a certain oilfield production tends to decrease along the years and only one smaller diameter pipeline would allow higher average flow temperatures compared to large diameter pipeline, providing great aspects of flow assurance and pressure drop. In smaller diameter pipelines, velocities are greater and the external area is smaller, allowing low heat transfer even during reduced volumetric flow rates. Thereby, petroleum rheology and smaller diameter pipelines might bring substantial improvements in terms of pressure drop reduction.

An important analysis could be done considering viscous oil flow (laminar regime) and isothermal features, adopting for example, average flow temperature and evaluate system capacity considering two parallel pipelines with distinct diameters $\left(D_{1}\right.$ and $\left.D_{2}\right)$ and single pipeline system $\left(D_{3}\right)$ with a large diameter. Equation 10 results from hydraulic definitions of parallel flow and evaluates the best system in terms of pressure drop. In this case, $\Delta \mathrm{P}$ is the pressure drop. If $\eta>1$, a single system is recommended. If $\eta<1$, a two parallel pipelines system is recommended. In case of $\eta=1$, both cases are accepted.

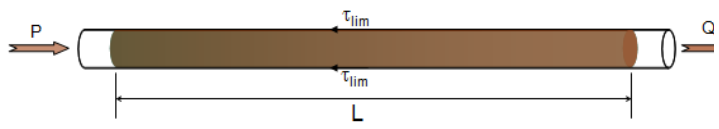

Figure 8. Illustration of fluid flow through pipeline

$$
\eta=\frac{\Delta P_{1}}{\Delta P_{3}}=\frac{\Delta P_{2}}{\Delta P_{3}}=\frac{\left(\frac{D_{3}}{D_{1}}\right)^{4}}{\left[1+\left(\frac{D_{2}}{D_{1}}\right)^{4}\right]}=\frac{\left(\frac{D_{3}}{D_{2}}\right)^{4}}{\left[1+\left(\frac{D_{1}}{D_{2}}\right)^{4}\right]}
$$

To obtain a similar relation for volumetric calculation, Eq. 11 is proposed.

$Q=Q_{1}\left[1+\left(\frac{D_{2}}{D_{1}}\right)^{4}\right]=Q_{2}\left[1+\left(\frac{D_{1}}{D_{2}}\right)^{4}\right]$

Drag reducers might be applied in smaller diameter pipeline during the first few years of production in order to improve flow performance. For example, during the first few years, volumetric flow rates are higher and oil flux more turbulent, more likely to pressure drop occurrences. Therefore, drag reducers application could be a solution. However, a combination of financial and laboratory analyses should be done to ensure improvements. In case of more viscous oil, this alternative might not be successful and strategies to reduce viscosity, such as electric heating and thermal insulation, should be adopted. Blend applications could also be useful.

\subsection{Non-Newtonian flow}

Non-Newtonian petroleum is characterized by rheological analysis in laboratory. Generally, these types of petroleum present yield stress as well as a power factor on shear rate. The rheological model is the described in Eq. 9. Rheological tests containing the oil to be studied and temperature variation are fundamental in designing an exportation system and evaluating risks associated to flow assurance aspects. It's important to consider temperatures that are below the paraffin precipitation zone. This zone is where generally might occur rheological changes, taking into considerations thermal exchanges with the seabed. It is a probable scenario during long stops. A simple model is obtained to evaluate required pump capacity by force balance of the static fluid inside the pipeline (Andreolli, 2009; Hilbert, 2010). This model is based on yield stress $\left(\tau_{\text {lim }}\right)$ that is measured in laboratory to estimate minimum pressure required to start flow. Figure 8 shows a simplified model of a pipeline of diameter $D$, containing oil gelling that presents limit flow strain. 
Performing force balance during flow imminence and considering forces related to pump pressure and reaction of friction force due to yield stress, it's possible to write Eq. 12. However, Eq. 12 could be rearranged generating Eq. 13 where pump pressure must satisfy the inequality below.

$P \cdot\left(\frac{\pi \cdot D^{2}}{4}\right)=\tau_{\lim } \cdot(\pi \cdot D \cdot L)$

$P \geq \frac{4 \cdot \tau_{\lim } \cdot L}{D}$

The yield stress $\left(\tau_{\text {lim }}\right)$ is measured during project phase according to oil tests. But, studies have shown that fluid $\tau_{\text {lim }}$ generated on real flow systems might vary along the pipeline and this variation has a dependency on diverse parameters, such as, thermal historic and shear stress that system was submitted to previously (Smith \& Ramsdem, 1978). The inequality generated on Eq. 13 might overestimate required pressure in three to five ( 3 to 5) times as revealed by Vankatesan and Creek (2010), who have shown studies using 12 inches diameter. The inequality provides a conservative result and more complex analyses could no longer be necessary if the pressure required is lower than pressure available. Among parameters that influence $\tau_{\text {lim }}$ are: fluid cooling rate, fluid formation time, and temperature. In addition, $\tau_{\text {lim }}$ varies along pipeline, being dependent of the flow historic conditions. It's necessary to understand the condition that oil was submitted to in order to generate gelling stages during flow. These required background information become oil flow modeling more complex (Smith \& Ramsden, 1978; Sestak et al., 1982).

Moreover, Eq. 12 should be integrated along pipeline extension according to Eq. 14, however, complexity is found on model acquisition that represents $\tau_{\lim }$ along pipeline. In the literature, many models were proposed in order to estimate $\tau_{\text {lim }}$, such as the model proposed by Sestak et al. (1982) which includes important parameters that influence $\tau_{\lim }$ behavior.

However, the state of the art indicates that more research is required to develop a better understanding of the problem, being able to improve mathematic models. To conclude, this field has large uncertainties that should be deeply explored in terms of physic behavior of a nonNewtonian fluid flow (Venkatesan \& Creek, 2010; Sestak et al., 1982; Bourgoyne et al., 1991).

$$
P \geq \frac{4}{D} \int_{0}^{L} \tau_{\lim } \cdot d L
$$

In terms of examples, the Brazilian Pre-salt presents non-Newtonian oils that when submitted to low temperatures could cause paraffin precipitation. Oils containing paraffin content tend to change the rheology due to paraffin precipitation, showing gel behavior. More studies in this field are in development phase, seeking improvements on models already established.

\section{CONCLUSION AND RECOMMENDATIONS}

This work revealed many aspects that must be acknowledged in an oil pipeline design project, such as:

1. The type of oil used. Laboratory tests should be done in order to characterize the oil to be studied. In case of more viscous oils, the influence of viscosity is directly related to pressure drop. On the other hand, less viscous oils are more likely to have problems associated to gelling;

2. Flow modeling should be done in order to provide an accurate understanding of the fluid in terms of fluid mechanics. In addition, aspects related to thermal modeling also should be acknowledged due to its complexity. When dealing with very viscous oil flow, thermal exchanges should be accurately predicted to avoid future issues;

3. Drag reducer applications for turbulent oil flow. Field tests may appear as an important phase, to evaluate the performance of selected products. The usage of these compounds might bring improvements in terms of pressure drop reduction during oil flow through pipeline, and also improvements in terms of pipeline diameter reduction, providing a great solution to subsea engineering;

4. Some considerations involving subsea engineering. This include the use of smallerdiameter pipelines that may appear to offer a great 
advantage related to cleaning operations, pigging operations, and also could improve productivity. In addition, parallel pipeline systems could also be an interesting alternative when combined to drag reducers, ensuring better performance during production peaks;

5. Mitigating alternatives. Strategies in order to avoid system implementation, electric heating, pipe-in-pipe application, adequate pigging system, and blend solutions with lighter oils.

\section{NOMENCLATURE}

FPSO - Floating Production Storage and Offloading

FSO - Floating Storage and Offloading

TLWP - Tension Leg Wellhead Platform

${ }^{\circ} \mathrm{API}$ - API stock tank gravity (degree)

$A-\operatorname{area}\left(\mathrm{m}^{2}\right)$

C-volumetric part per million (vppm)

$\mathrm{D}$ - diameter $(\mathrm{m})$

$\mathrm{g}-$ gravity $\left(\mathrm{m} / \mathrm{s}^{2}\right)$

$\mathrm{HP}$ - pressure drop (m)

$\mathrm{K}$ - non-Newtonian fluid parameter

$\mathrm{L}$ - pipeline length $(\mathrm{m})$

$n$ - power factor

$P$ - pressure $\left(\mathrm{kgf} / \mathrm{cm}^{2}\right)$

$\mathrm{Q}$ - volumetric flow rate $\left(\mathrm{m}^{3} /\right.$ day)

Re - Reynolds number

$\mathrm{T}$ - temperature $\left({ }^{\circ} \mathrm{C}\right)$

$\mathrm{V}$ - velocity $(\mathrm{m} / \mathrm{s})$

$x$ - length $(m)(0<x<L)$

$\varepsilon$-absolute roughness

$\eta$-coefficient

$\mu-$ viscosity (cP)

$\rho$ - density $\left(\mathrm{g} / \mathrm{cm}^{3}\right)$

$\tau$ - shear stress

$\tau_{\lim }-$ yield stress

\section{REFERENCES}

Ajienka, J. A. \& Ikoku, C. U. Criteria for the design of wax crude oil pipelines: maximum pump (horsepower) pressure requirement. Journal of Petroleum Science and Engineering, v. 13, p. 8794, 1995.

http://dx.doi.org/10.1016/0920-4105(94)00064-B

Andreolli, I.; Borges, J. P. F.; Gaspari, E. F. Desafios da exportação de óleos pesados através de oleodutos em águas profundas. Rio Oil \& Gas and Conference, Rio de Janeiro, 2008.Brazil's Energy and Mines Ministry (MME). National Energy Balance (2007). MME: Brasilia, 2008.

Andreolli, I. Introdução a Elevação e Escoamento Monofásico e Multifásico de Petróleo. Livro em publicação. Rio de Janeiro. Registrado na Biblioteca Nacional. 2015.

Andreolli, I. Oil flow in deep waters: Comparative study between light oils and heavy oils. Rio Pipeline Conference and Exposition, Rio de Janeiro, 2009.

Bannwart, A. C. Modeling aspects of oil-water core-annular flows. Journal of Petroleum Science and Engineering, v. 32, p.127-143, 2001. http://dx.doi.org/10.1016/S0920-4105(01)00155-3

Barnes, H.A. Thixotropy - a review. Journal of Non-Newtonian Fluid Mechanics, v.70, p. 1-33, 1979.

http://dx.doi.org/10.1016/S0377-0257(97)00004-9

Bernardo, D. A. L.; Andreolli, I. Exportação de petróleo através de oleodutos: alguns aspectos importantes a serem considerados no projeto. Rio Oil \& Gas and Conference, Rio de Janeiro, 2014.

Bessa, M. G. Estudo experimental do escoamento laminar em dutos de óleos pesados com viscosidade dependente da temperatura. Dissertação de Mestrado, Pontifícia Universidade Católica (PUC)-RIO, 2013.

Bobok, E.; Magyari, D.; Udvardi, G. Heavy oil transport through lubricated pipeline. SPE European Petroleum Conference and Exhibition, Milan, Italy, 1996.

http://dx.doi.org/10.2118/36841-ms 
Bourgoyne, A. T. J.; Chenevert, M. E.; Keith K.; Young, M. F.S. J. Applied Drilling Engineering. SPE Textbook Series, $2^{\text {nd }}$ edition, Texas, USA, 1991.

Cardoso, C. B.; Alves, I. N.; Ribeiro, G. S. Management of flow assurance constraints, Offshore Technology Conference, Houston, Texas, 2008.

Degiorgis, G.L.; Maturano, S.; Garay, M.; Galliano, G. R.; Fornes, A. Oil mixture viscosity behavior: Use in pipeline design. SPE Latin American and Caribbean Petroleum Engineering Conference, Buenos Aires, Argentina, 2001. http://dx.doi.org/10.2118/69420-MS

Desouky, S. E. M. A new laminar-turbulenttransition criterion for pseudoplastic fluids. Journal of Petroleum Science and Engineering, v. 5, p. 285291, 1991.

http://dx.doi.org/10.1016/0920-4105(91)90044-N

Dixon, M. Pipe-in-Pipe: Thermal management for effective flow assurance. Offshore Technology Conference, Houston, Texas, 2013.

http://dx.doi.org/10.4043/24122-ms

Dodger, D. G \& Metzener, A. B. Turbulent flow of non-Newtonian system, American Institute of Chemical Engineers (AIChE) Journal, v. 5, p. 189204, 1959.

Farshad, F.; Rieke, H.; Garber, J. New developments in surface roughness measurements, characterization and modeling fluid flow in pipe. Journal of Petroleum Science and Engineering, v. 29, p. 139-150, 2001.

http://dx.doi.org/10.1016/S0920-4105(01)00096-1

Ghannam, M. T.; Hasan, S. W.; Jdayil, B. A.; Esmail, N. Rheological properties of heavy and light oil mixture for improving flowability. Journal of Petroleum Science and Engineering, v.81, p.122126, 2012.

http://dx.doi.org/10.1016/i.petrol.2011.12.024

Graham, M. D. Drag reduction in turbulent flow of polymer solution. The British Society of Rheology, p. 143-170, 2004.

Hilbert, J. Flow assurance: Wax deposition and gelling in subsea oil pipeline. SPE Asia Pacific Oil \& Gas Conference and Exhibition, Brisbane, Queensland, 2010.
International Energy Agency (IEA). Oil Marker Report. Available at:

https://www.iea.org/oilmarketreport/omrpublic/ accessed on November 27 2014.

Jiménez, J. The Global Geometry of Turbulence: Impact of Nonlinear Dynamics, New York, Plenum Press, 1991. http://dx.doi.org/10.1007/978-1-46153750-2

Jiménez, J. Turbulent flow over rough walls. Journal of Fluid Mechanics, v. 36, p. 173-196, 2004.

http://dx.doi.org/10.1146/annurev.fluid.36.050802.122 $\underline{103}$

Junior, J. G. S.; Paternost, G. M.; Condessa, D. S. Flow assurance challenges in the Papa-Terra project. Offshore Technology Conference, Houston, Texas, 2009.

http://dx.doi.org/10.4043/19864-MS

Komolgorov, A. N. Dissipation of energy in locally isotropic turbulence. Dokl Akad Nauk SSSR 33, p. 19-21, 1941.

Machado, J. C. V. Reologia e Escoamento de Fluidos, Rio de Janeiro: Interciência, p.257, 2002.

McDermott, P. \& Sathananthan, R. Active heating for life of field flow assurance. Offshore Technology Conference, Houston, Texas, 2014. http://dx.doi.org/10.4043/25107-ms

Mendes, P. R. S.; Soares, F. S. M. A.; Ziglio C. M.; Gonçalves, M. Startup flow of gelled crude in pipelines. Journal of Non-Newtonian Fluids, v.179, p. 23-31, 2012.

http://dx.doi.org/10.1016/i.jnnfm.2012.05.003

Moody, L. F. Friction factors for pipe flow. Transactions of the American Institute of Mining (AIME), v. 8, p. 671-684, 1944.

Palou, R. M.; Mosqueira, M. L.; Rendón, B. Z.; Juárez, E. M.; Huicochea, C. B.; López, J. C. C.; Alburto, J. Transportation of heavy and extra heavy cruse oil by pipeline: A review. Journal of Petroleum Science and Engineering, v. 75, p. 274282, 2011.

http://dx.doi.org/10.1016/i.petrol.2010.11.020 
Peysson, Y., Bensakhria, A., Antonini, G., Argiller, J.F. Pipeline lubrication of heavy oil: experimental investigation of flow and restart problems. International Thermal Operation and Heavy Oil Simposium. Calgary, Alberta, 2005.

Pope, S. B. Turbulent flows. Cambridge, Cambridge University Press, 2000.

http://dx.doi.org/10.1017/CBO9780511840531

Sestak, J.; Houska, M.; Zitney, R. Mixing of thixotropic fluids. Journal of Rheology, v. 26, p 459-475, 1982. http://dx.doi.org/10.1122/1.549673

Smith, P. B. \& Ramsden, R. M. J. The prediction of oil gelation in submarine pipe and the pressure required for restarting flow. European Offshore Petroleum conference and Exhibition, London, United Kingdom, 1978.

Tennekes, H. \& Lumley, J. L. A first course in turbulence, Massachusetts Institute of Technology (MIT) Press, 1972.
Toonder, J. M. J. D. Drag reduction by polymer additives in a turbulent pipe flow: numerical and laboratory experiments. Journal of Fluid Mechanics, v. 337, p. 193-231, 1997. http://dx.doi.org/10.1017/S0022112097004850

Vankatesan, R. \& Creek, J. Wax deposition and rheology: progress and problems from an operator. Chevron Energy technology Company. Offshore Technology and Conference, Houston, Texas, 2010. http://dx.doi.org/10.4043/20668-ms

Wahaibi, T. A.; Smith, M.; Angeli, P. Effect of drag reducing polymers on horizontal oil-water flows. Journal of Petroleum Science and Engineering, v. 57, p.334-346, 2007. http://dx.doi.org/10.1016/j.petrol.2006.11.002 